\title{
A TAXONOMY FOR EVALUATION AND COMPARISON OF FINANCIAL PERFORMANCE OF INDIAN IT COMPANIES
}

\author{
*Akshita Jain $\quad * *$ Dr. Subramanyam Ganti
}

\begin{abstract}
:
The term paper is mainly presented to demonstrate the use of Taxonomic Method designed by Polish Mathematicians. The paper investigates performance of 20 IT Companies of India in light of 10 financial indicators. The methodology identifies the companies that show similar performance but different from other companies. Further, the paper also explores the cluster analysis of the companies and analyses the pattern to cluster. The taxonomy here also assists the recognition of the company performance and provides relevant information both to investors and the existing shareholders to continue to invest in the company and for making new investment strategies.
\end{abstract}

Keywords : Taxonomy method, financial indicators, investors, investment strategies.

\section{Introduction}

The crisis of the Indian market with the depreciation of rupee has raised the interest of comparison of companies. Facing with much turbulent in the market, it has now become necessary to compare companies on their performance and allow investors to decide. Financial performance will not only indicate the company profitability but will also help in shortterm and long-term forecasting of the company growth. The proposed taxonomy known as Wroclaw taxonomy was first designed by Polish mathematicians in 1952 in order to obtain a statistical method of determining homogeneous units or 'types of things' in an n-dimensional vectorial space, without the use of regression, variance or correlation analysis. The taxonomic method is able to achieve the division of a set into more or less homogeneous subsets; provides a useful tool for interpolation and extrapolation of statistical data and sets up a measure to compare performance and profitability of a company. This taxonomy has been analysed in context with the companies. The findings of the method can be applied to ascertain the company with the highest performance and moreover, the results of the analysis provide insight information about the company to a probable investor. The paper is outlined as follows: Section II introduces the theoretical framework which describes the method in detail. The methodology being followed and the various indicators used are discussed in Section III. Section IV describes the results and findings of the research, taking a data set of 20 companies and 10 performance

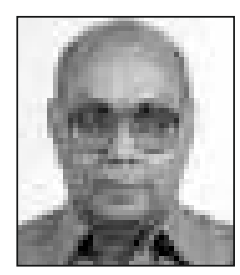

**Dr. Subramanyam Ganti

Visiting Professor

Gitam School of International Business Gitam University

Visakhapatnam 
indicators and in the last Section V concludes the paper.

\section{Theoretical Framework}

In this section, the taxonomic method is described in detail to understand the theory behind and application of the method clearly. To start with, let us suppose $\mathrm{Z}$ denotes a set of $\mathrm{N}$ points representing units to compare $1,2, \ldots, \mathrm{N}$ for a group of variables/ indicators $1,2, \ldots ., \mathrm{m}$ which can be represented by the following matrix:

\section{Matrix 1}

$$
\left[\begin{array}{lllll}
\mathrm{x}_{11} & \mathrm{x}_{12} & \cdot & \cdot & \mathrm{x}_{1 \mathrm{~m}} \\
\mathrm{x}_{21} & \mathrm{x}_{22} & \cdot & \cdot & \mathrm{x}_{2 \mathrm{~m}} \\
\cdot & \cdot & \cdot & \cdot & \cdot \\
\cdot & \cdot & \cdot & \cdot & \cdot \\
\cdot & \cdot & \cdot & \cdot & \cdot \\
\cdot & \cdot & \cdot & \cdot & \cdot \\
\mathrm{x}_{\mathrm{N} 1} & \mathrm{x}_{\mathrm{N} 2} & \cdot & \cdot & \mathrm{x}_{\mathrm{Nm}}
\end{array}\right]
$$

Thus, every unit is represented by a point or vector in an n-dimensional space. In order to eliminate the influence of various measurement units, a normalisation of particular variables is carried out by the following formula:

and

$$
\frac{\frac{2-i}{g}}{g}, \text { where } \mathrm{j}=1,2, \ldots, \mathrm{m}
$$

$$
\overline{x_{j}}=\frac{1}{N} \sum_{i=1}^{W} x_{j} \quad \text { and } \quad s_{j}=\left[\frac{1}{N} \sum_{l=1}^{W}\left(x_{i j}-\overline{x_{j}}\right)^{2}\right]^{1 / 2}
$$

The normalisation procedure now results in a new matrix, where every unit is represented by a standardized point or vector in an m-dimensional space.

The normalised matrix would be:

Matrix 2

$$
\left[\begin{array}{lllll}
D_{11} & D_{12} & \cdot & \cdot & D_{1 m} \\
D_{21} & D_{22} & \cdot & \cdot & D_{2 m} \\
\cdot & \cdot & \cdot & \cdot & \cdot \\
\cdot & \cdot & \cdot & \cdot & \cdot \\
\cdot & \cdot & \cdot & \cdot & \cdot \\
\cdot & \cdot & \cdot & \cdot & \cdot \\
D_{N 1} & D_{N 2} & \cdot & \cdot & D_{N m}
\end{array}\right]
$$


where

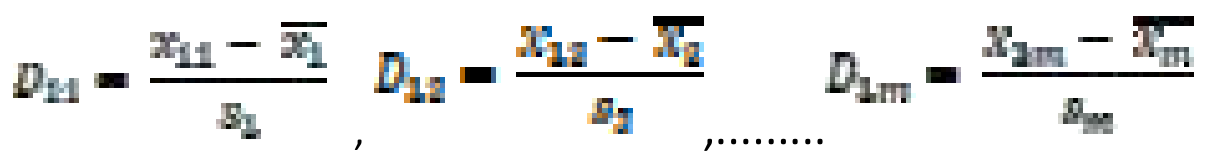

From the above standardised matrix, the next step is to get the difference or 'distance' from each point to every other point $(1,2, \ldots ., \mathrm{N})$ for each of the $\mathrm{m}$ variables, which results in another interim matrix:

\section{Matrix 3}

$\left[\begin{array}{lllll}D_{11}-D_{21} & D_{12}-D_{22} & \cdot & \cdot & D_{1 m}-D_{2 m} \\ D_{11}-D_{31} & D_{12}-D_{32} & \cdot & \cdot & D_{1 m}-D_{3 m} \\ \cdot & \cdot & \cdot & \cdot & \cdot \\ \cdot & \cdot & \cdot & \cdot & \cdot \\ \cdot & \cdot & \cdot & \cdot & \cdot \\ \cdot & \cdot & \cdot & \cdot & \cdot \\ D_{N-1}-D_{N 1} & D_{(N-1) 2}-D_{N 2} & \cdot & \cdot & D_{(N-1) m}-D_{N m}\end{array}\right]$

Finally, distance between two points $\mathrm{Pa}$ and $\mathrm{Pb}$ for any set or subset of $\mathrm{m}$ variables is derived by the following formula:

$$
c_{a b}=\left[\sum_{k-1}^{k}\left(D_{a k}-D_{b k}\right)^{2}\right]^{1 / 2}
$$

where the following relationships are apparent:

$\mathrm{c}_{\mathrm{aa}}=0 ; \mathrm{c}_{\mathrm{ab}}=\mathrm{c}_{\mathrm{ba}}$ and $\mathrm{c}_{\mathrm{ab}}<=\mathrm{c}_{\mathrm{ak}}+\mathrm{c}_{\mathrm{kb}}$

The above formula results in a symmetric matrix termed as the distance matrix:

Matrix 4

$$
\left[\begin{array}{lllll}
0 & c_{12} & \cdot & \cdot & c_{1 N} \\
c_{21} & 0 & \cdot & \cdot & c_{2 N} \\
\cdot & \cdot & \cdot & \cdot & \cdot \\
\cdot & \cdot & \cdot & \cdot & \cdot \\
\cdot & \cdot & \cdot & \cdot & \cdot \\
c_{N 1} & c_{N 2} & \cdot & \cdot & 0
\end{array}\right]
$$


Within a given set of units, this distance of each unit to every other is a synthetic or composite distance. It is a mathematical expression of several distances on each of several dimensions with which countries can be compared.

Once the matrix 4 is obtained, the minimum distance from a given unit to all other units in the row can be found which is the index of resemblance-the closest point within a given frame of reference.

The next step is to determine the critical region between which the minimum distance found is considered as significant. The critical minimum distance is derived by the formula:

$$
a_{[+\bar{j}}=\bar{c}+2 \mathrm{~g}
$$

where

$$
\bar{E}=\frac{1}{N} Z_{I=1}^{W}
$$

is the arithmetic mean of the distances cj, the minimum in each row of the distance matrix and

$$
s_{a}=\left[\frac{1}{N} y_{I=1}^{N}\left(c_{1}-\bar{C}\right)^{2}\right]^{1 / 2}
$$

is the standard deviation of the minimum distances in each row. The number of $\mathrm{N}$ elements in the set can be reduced further with the second critical value:

$$
\sigma_{-[-]}=\bar{c}-2 \mathrm{~g}
$$

The critical value may be considered as a measure of resemblance - the greater is c $(+)$, the smaller is the resemblance between all possible pairs of points.

The other use of this taxonomic method is to derive the patterns and measures of development. The object is to find a unit or units upon which to model oneself, but which has to be on a higher level. For each variable in each set of $\mathrm{N}$, there exists an 'ideal' value, which is the best value held within the group by a given unit. Hence, find the standardised value which is the highest for variables which have a stimulant nature and the highest negative value for those variables which to tend to hamper performance. The pattern of development or performance $\left(\mathrm{c}_{\mathrm{io}}\right)$ is simply the distance of each unit in the matrix from the ideal one $(\mathrm{O})$ as derived by the following formula:

$$
c_{\text {lo }}=\left[\sum_{k-1}\left(D_{k}-D_{o k}\right)^{2}\right]^{1 / 2}
$$

where $\mathrm{i}=1,2, \ldots . ., \mathrm{N}$ and $\mathrm{O}$ is the maximum standardised value as determined from Matrix 2 . The larger is the number cio the greater is the distance from this particular unit to its potential high point within the set or subset. 
The measure of development or performance is a method of simulating the percentage of development in a particular area. In other words, it is a function of the pattern of development and the critical distance from the ideal. The following formula is applied:

where

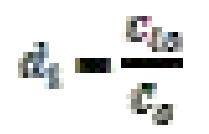

$$
G_{\mathrm{g}}=\overline{\mathrm{F}_{\mathrm{g}}}+2 \mathrm{~g}
$$

and

$$
\overline{E_{L a}}=\frac{1}{N} E_{i=1}^{N} E_{\mathrm{fo}} \quad \text { (the mean of the pattern of development) }
$$

and

$$
s_{10}=\left[\frac{1}{N} Z_{I=1}\left(c_{t o}-\overline{C_{i o}}\right)^{2}\right]^{1 / 2}
$$

In the above equation di shall be called the measure of development. The closer $\mathrm{d}$ is to 0 the more developed or highest performer is the unit, and the closer to 1 , the less developed or least performer the unit.

\section{Limitations}

The biggest limitation of the method is that it cannot be applied to different set of units. It can only be applied to homogeneous set of units. Further, only companies in the same sector or industry can be compared using this method. There is ambiguity of finding the closest point to the units taken which in real scenario can be overruled. The findings and results of the method are not universal and subject to data set considered.

\section{Cluster Analysis}

The cluster analysis is the method of identifying the groups of individuals or objects that are similar to each other but different from individuals in other groups can be intellectually satisfying, profitable, or sometimes both. The purpose of the analysis is to determine the similar nature and similar performing individuals within a group also. Furthermore, the aim is to group individuals with homogeneous set of preferences and performance. Since the taxonomic method is applied to homogeneous set only, cluster analysis is a follow-up of the taxonomic method discussed here to see the pattern of performance of the units or individuals observed. Clustering depends on the method used in the analysis. Here, hierarchal clustering is used which involves the calculation of distance matrix which is already done in the taxonomic method. Distance is a measure of how far apart two objects are, while similarity measures how similar two objects are. For cases that are alike, distance measures are small and similarity measures are large. On the basis of the distance matrix, the data is analysed and clustered.

The method is applied to compare the performance of companies. A set of 20 companies and 10 indicators is taken upon which the analysis will be carried out. 


\section{Methodology}

Taxonomies are meant to classify groups. The term 'taxonomy' refers to the theory and practice of producing classification schemes. Thus, constructing a classification is a taxonomic process with rules on how to form and represent groups. Taxonomies are useful as they are able to reduce the complexity of the population studied into easily recallable macro classes. The theoretical framework which was discussed in the previous section orders and represents complex phenomena in a simple manner through a matrix, a table, a map, etc. The methodology used in this research is based on the theoretical framework provided above and makes available the comparison of performance between companies. The companies should be homogeneous and must belong to same sector are taken from IT sector. Following are the companies that have been taken for the analysis:

1. H C L Technologies Ltd.

2. Hewlett-Packard Globalsoft Pvt. Ltd.

3. Infosys Ltd.

4. Infotech Enterprises Ltd.

5. Mphasis Ltd.

6. Oracle Financial Services Software Ltd.

7. Patni Computer Systems Ltd.

8. Satyam Computer Services Ltd. [Merged]

9. Tata Consultancy Services Ltd. (TCS)

10. Tata Infotech Ltd. [Merged]

11. Wipro Ltd.

12. Zylog Systems Ltd.

13. Tech Mahindra Ltd.

14. Vakrangee Ltd.

15. Polaris Financial Technology Ltd.

16. Flextronics Software Systems Ltd. [Merged]

17. Acropetal Technologies Ltd.

18. Hexaware Technologies Ltd.
19. K P I T Technologies Ltd.

20. Persistent Systems Ltd.

The source of data is Prowess 4, CMIE Database. The analysis is done with these 20

countries and the following 10 performance indicators for the analysis of the performance of the companies:

1. EPS: A company's earnings per share (EPS) ratio allow to measure earnings in relation to every share on issue. This is done by dividing the company's net income by the average weighted number of shares on issue. It serves as an indicator of company's profitability. The more the EPS is, the more company is efficient in allocating its profit to each outstanding share of common stock.

2. Current Ratio: It is the ratio of current assets to current liabilities. The concept behind this ratio is to ascertain whether a company's short-term assets (cash, cash equivalents, marketable securities, receivables and inventory) are readily available to pay off its short-term liabilities (notes payable, current portion of term debt, payables, accrued expenses and taxes). In theory, the higher the current ratio, the better. A ratio of $2: 1$ is usually considered the benchmark; however, this may vary across industries. A ratio of less than one suggests that the company may not have sufficient resources to settle its short-term debt obligations if they fell due today.

The following formula is used to evaluate current ratio:

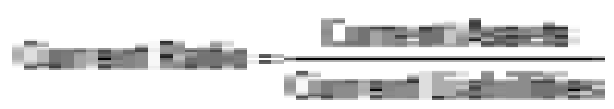


3. Net Profit: It is the earnings of the company earned after taking up the operations i.e. sale and purchase of goods. Net Profit is the profit after tax is paid. It is a measure of the profitability of a venture after accounting for all costs. Higher the profits more profitable the company is.

4. Sales Ratio: This ratio, which is expressed as a percentage, compares a company's operating cash flow to its net sales or revenues, which gives investors an idea of the company's ability to turn sales into cash. It would be worrisome to see a company's sales grow without a parallel growth in operating cash flow. Positive and negative changes in a company's terms of sale and/or the collection experience of its accounts receivable will show up in this indicator. Following is the formula used:

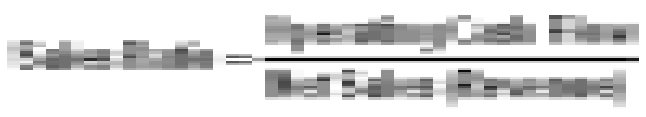

5. Net Profit Ratio: It is the ratio of net profit to sales. It indicates how much of sales revenue of a company would remain after all costs have been taken into account. Net profit (NP) ratio is a useful tool to measure the overall profitability of the business. A high ratio indicates the efficient management of the affairs of business. The formula used is as follows:

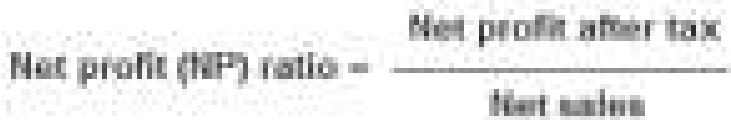

6. Turnover: Turnover is sometimes the name for a measure of how quickly inventory is sold. A high turnover means that goods are sold quickly, while a low turnover means that goods are sold more slowly.
7. Expense Ratio: It is also referred as expenses-to-sales ratio. It measures the operating expenses of a business shown on the profit and loss statement, with the gross sales of the business that are also shown on the profit and loss statement. This ratio is a quick indicator of rising or decreasing costs or rising or declining sales. In a period of inflation, when costs are rising, the expense-to-sales ratio might increase because it is more expensive to produce a sale. Increased efficiency in the production process can also affect the expense-to-sales ratio. Over time, as efficiency improves, it could take less time to produce a certain good. When this happens, the expense-tosales ratio should decrease. It is calculated as:

$$
\text { Expense Ratio } \frac{\text { Total Hrpanas }}{\text { Salan }}
$$

8. Return on Assets: Return on assets, commonly referred to as ROA, is a ratio of sales/income to total assets. It is a measurement of management performance. ROA tells the investor how well a company uses its assets to generate income. The higher the return, the more efficient management is in utilizing its asset base. Following is the formula used:

$$
\text { Return on Assets }=\frac{\text { Income }}{\text { Total Aarets }}
$$

A rising $\mathrm{ROA}$, for instance, may initially appear good, but turn out to be unimpressive if other companies in its industry have been posting higher returns and greater improvements in ROA. The ROA ratio may thus be more useful when compared to the risk free rate of return. 
Technically, a company should produce an ROA higher than the risk free rate of return to be rewarded for the additional risks involved in operating the business. If a company's ROA is equal or even less than the risk free rate, investors should think twice as they would be better off just purchasing a bond with a guaranteed yield.

9. Enterprise Value: A measure of a company's value, often used as an alternative to straightforward market capitalization. Enterprise value is calculated as market cap plus debt, minority interest and preferred shares, minus total cash and cash equivalents. It attempts to measure the value of a company's business instead of measuring the value of the company. It is the measure for calculating how much it would cost to buy a company's business free of its debts and liabilities. It can be thought of as a theoretical takeover price of a company's business. The enterprise value is calculated by the following formula:

Enterprise Value $=$ Market Capitalization + Debt + Preferred Share Capital + Minority Interest - Cash and cash equivalents

10. Wages-to-Sales Ratio: A wages to sales ratio is a simple accounting calculation that allows a retail business to determine the value of its workforce as a function of its revenue. It is calculated as:

\section{Wages-to-Sales Ratio $=\frac{\text { Trmpansutim in Emplopes: }}{\text { Riles }}$}

As a KPI, a wages to sales ratio indicates how well a retail business and its individual sales staff members, is performing. When a wages to sales ratio is higher, it means that the sales staff is performing poorly or having difficulty selling merchandise. When the wages to sales ratio falls, it indicates greater efficiency and higher profits for the retailer. A retail store owner can use this information to track how well individual sales staff members perform over time. Wages to sales ratios can also track the store's overall sales efficiency, or compare one department, month or day of the week to another.

These indicators determine the profitability and performance of the company. The data for each indicator for each company is taken from Prowess 4. Then, the normalisation is carried on these indicators using the standardisation method mentioned in the previous section.

All the complex calculations due to multiindicators and a set of 20 companies is taken care by the application of MS Excel, which provides all the results and findings that are analysed in the next section. Cluster analysis is done with the help of ' $R$ ', a statistical package.

\section{Results and Findings}

The section is going to discuss the results and findings of the method. The Table 1 is a $20 \times 10$ matrix consisting of 20 companies and 10 indicators which is the Matrix 1 of the method. As can be seen, it contains the actual values of the ten performance indicators for each country and also, it consists of means and standard deviations of each indicator across the companies. Since there are certain indicators with different measurement units, Table 2 which is equivalent to Matrix 2 of the method contains the standardised values for the indicators for each company calculated using the formula 
Table 1/Matrix 1: Performance Indicators- IT Companies

\begin{tabular}{|c|c|c|c|c|c|c|c|c|c|c|}
\hline Company Name & EPS & $\begin{array}{c}\text { Current } \\
\text { Ratio }\end{array}$ & Net Profit & Sales ratio & $\begin{array}{c}\text { Net Profit } \\
\text { Ratio }\end{array}$ & Turnover & $\begin{array}{c}\text { Expense } \\
\text { Ratio }\end{array}$ & $\begin{array}{c}\text { Return On } \\
\text { Assets }\end{array}$ & $\begin{array}{c}\text { Enterprise } \\
\text { value }\end{array}$ & $\begin{array}{l}\text { Wages-to- } \\
\text { Sales Ratio }\end{array}$ \\
\hline $\mathrm{HCL}$ & 28.13 & 1.0 & 19503.7 & 0.23 & 0.22 & 67.27 & 0.82 & 0.76 & 804641.32 & 0.45 \\
\hline HP & 28.08 & 3.7 & 974.2 & 0.12 & 0.07 & 5.56 & 0.94 & 1.45 & 25980.36 & 0.64 \\
\hline Infosys & 158.75 & 4.3 & 91160 & 0.18 & 0.25 & 386.07 & 0.82 & 0.90 & 1699824.95 & 0.54 \\
\hline Infotech & 16.68 & 3.1 & 1843.4 & 0.13 & 0.18 & 2.24 & 0.87 & 0.78 & 20309.95 & 0.48 \\
\hline Mphasis & 28.23 & 1.3 & 6110 & 0.21 & 0.17 & 35.34 & 0.88 & 0.73 & 74132.32 & 0.43 \\
\hline Oracle & 118.17 & 2.7 & 10292.6 & 0.40 & 0.35 & 5.57 & 0.82 & 0.36 & 221039.29 & 0.49 \\
\hline Patni & 37.44 & 0.7 & 4997.8 & 0.12 & 0.23 & 20.48 & 0.84 & 0.53 & 53495.22 & 0.59 \\
\hline Satyam & 5.27 & 1.2 & 12028 & 0.12 & 0.20 & 681.44 & 0.94 & 0.91 & 108166.25 & 0.61 \\
\hline TCS & 65.33 & 2.0 & 127863.4 & 0.19 & 0.26 & 698.21 & 0.78 & 1.17 & 4281162.45 & 0.50 \\
\hline Tata Infotech & 40.61 & 1.5 & 802.4 & 0.05 & 0.11 & 2.2 & 0.94 & 1.77 & 14058.59 & 0.20 \\
\hline Wipro & 22.94 & 2.0 & 56502 & 0.18 & 0.17 & 539.26 & 0.87 & 0.84 & 1233832.45 & 0.48 \\
\hline Zylog & 106.02 & 4.5 & 1738.9 & 0.06 & 0.14 & 2.86 & 0.87 & 0.78 & 3626.1 & 0.30 \\
\hline Tech Mahindra & 50.93 & 1.1 & 6525 & 0.11 & 0.11 & 196.71 & 0.90 & 0.82 & 379296.92 & 0.42 \\
\hline Vakrangee & 2.17 & 3.4 & 1092.7 & 0.05 & 0.07 & 24.33 & 0.95 & 1.15 & 38621.48 & 0.02 \\
\hline Polaris & 16.78 & 1.3 & 1645.9 & 0.06 & 0.09 & 18.88 & 0.94 & 1.12 & 11200.28 & 0.73 \\
\hline Flextronics & 50.16 & 1.7 & 1345.2 & 0.17 & 0.20 & 6.17 & 0.80 & 0.73 & 23000.5 & 0.47 \\
\hline Acropetal & 7.11 & 2.2 & 290.4 & 0.09 & 0.15 & 0.05 & 0.91 & 0.49 & 653.29 & 0.51 \\
\hline Hexaware & 9.63 & 1.2 & 2856 & 0.19 & 0.31 & 6.93 & 0.74 & 0.73 & 35498.2 & 0.48 \\
\hline $\mathrm{KPIT}$ & 5.44 & 1.8 & 1030.5 & 0.16 & 0.14 & 4.58 & 0.87 & 0.54 & 27223.61 & 0.50 \\
\hline Persistent & 45.45 & 2.3 & 1818.1 & 0.19 & 0.18 & 14.98 & 0.86 & 0.88 & 24208.2 & 0.49 \\
\hline Mean & 42.166 & 2.2 & 17521.01 & 0.15 & 0.18 & 135.9565 & 0.87 & 0.87 & 453998.59 & 0.47 \\
\hline Standard Deviation & 41.68 & 1.12 & 34392.61 & 0.08 & 0.08 & 237.12 & 0.06 & 0.33 & 1012658.47 & 0.15 \\
\hline
\end{tabular}

Table 2/Matrix 2: Standardised Performance Indicators-IT Companies

\begin{tabular}{|c|c|c|c|c|c|c|c|c|c|c|}
\hline Company Name & EPS & $\begin{array}{c}\text { Current } \\
\text { Ratio }\end{array}$ & Net Profit & Sales ratio & $\begin{array}{c}\text { Net Profit } \\
\text { Ratio }\end{array}$ & Turnover & $\begin{array}{c}\text { Expense } \\
\text { Ratio }\end{array}$ & $\begin{array}{c}\text { Return On } \\
\text { Assets }\end{array}$ & $\begin{array}{c}\text { Enterprise } \\
\text { value }\end{array}$ & $\begin{array}{l}\text { Wages-to- } \\
\text { Sales Ratio }\end{array}$ \\
\hline $\mathrm{HCL}$ & -0.34 & -1.09 & 0.06 & 0.97 & 0.50 & -0.29 & -0.92 & -0.32 & 0.35 & -0.15 \\
\hline HP & -0.34 & 1.34 & -0.48 & -0.34 & -1.32 & -0.55 & 1.21 & 1.76 & -0.42 & 1.14 \\
\hline Infosys & 2.80 & 1.86 & 2.14 & 0.34 & 0.86 & 1.05 & -0.90 & 0.09 & 1.23 & 0.49 \\
\hline Infotech & -0.61 & 0.83 & -0.46 & -0.23 & -0.05 & -0.56 & -0.04 & -0.28 & -0.43 & 0.09 \\
\hline Mphasis & -0.33 & -0.80 & -0.33 & 0.73 & -0.08 & -0.42 & 0.18 & -0.43 & -0.38 & -0.26 \\
\hline Oracle & 1.82 & 0.49 & -0.21 & 3.16 & 2.15 & -0.55 & -0.76 & -1.56 & -0.23 & 0.15 \\
\hline Patni & -0.11 & -1.32 & -0.36 & -0.33 & 0.66 & -0.49 & -0.57 & -1.03 & -0.40 & 0.82 \\
\hline Satyam & -0.89 & -0.88 & -0.16 & -0.37 & 0.29 & 2.30 & 1.13 & 0.12 & -0.34 & 0.91 \\
\hline TCS & 0.56 & -0.17 & 3.21 & 0.49 & 1.06 & 2.37 & -1.45 & 0.91 & 3.78 & 0.18 \\
\hline Tata Infotech & -0.04 & -0.62 & -0.49 & -1.31 & -0.93 & -0.56 & 1.09 & 2.71 & -0.43 & -1.81 \\
\hline Wipro & -0.46 & -0.19 & 1.13 & 0.43 & -0.12 & 1.70 & 0.08 & -0.09 & 0.77 & 0.09 \\
\hline Zylog & 1.53 & 2.06 & -0.46 & -1.18 & -0.46 & -0.56 & 0.00 & -0.26 & -0.44 & -1.11 \\
\hline Tech Mahindra & 0.21 & -0.99 & -0.32 & -0.55 & -0.89 & 0.26 & 0.58 & -0.15 & -0.07 & -0.32 \\
\hline Vakrangee & -0.96 & 1.07 & -0.48 & -1.25 & -1.37 & -0.47 & 1.25 & 0.85 & -0.41 & -3.02 \\
\hline Polaris & -0.61 & -0.83 & -0.46 & -1.11 & -1.14 & -0.49 & 1.10 & 0.77 & -0.44 & 1.71 \\
\hline Flextronics & 0.19 & -0.45 & -0.47 & 0.30 & 0.28 & -0.55 & -1.10 & -0.42 & -0.43 & 0.03 \\
\hline Acropetal & -0.84 & 0.00 & -0.50 & -0.76 & -0.31 & -0.57 & 0.66 & -1.16 & -0.45 & 0.28 \\
\hline Hexaware & -0.78 & -0.87 & -0.43 & 0.48 & 1.65 & -0.54 & -2.22 & -0.43 & -0.41 & 0.04 \\
\hline $\mathrm{KPIT}$ & -0.88 & -0.37 & -0.48 & 0.16 & -0.45 & -0.55 & -0.02 & -1.01 & -0.42 & 0.21 \\
\hline Persistent & 0.08 & 0.08 & -0.46 & 0.49 & 0.04 & -0.51 & -0.19 & 0.04 & -0.42 & 0.10 \\
\hline
\end{tabular}

After Matrix 2 is obtained, the distance of each company from every other company for each indicator is calculated and using the formula for cab, the symmetric distance Matrix 4 is presented below with the final column showing the minimum distance (cj) in each row with the following statistics summary for the Matrix 4: 


\section{$\bar{c} \mathbf{n} 0.74$}

$\mathrm{S}_{\mathrm{c}}=0.34$

Critical model distance, $\mathrm{c}(+)=1.41$

Clearly, all the minimum distances lies within the critical model distance. The closest company to HCL for these ten variables is Flextronics with a distance of 0.47. Similarly for other companies, the closest company to HP is Polaris, closest to Infosys is Wipro, to Mphasis is Persistent, to Oracle is HCL, to Patni is Flextronics, to Satyam is Wipro, to TCS Wipro and Infosys are on the equal distance, to Tata Infotech is Vankragee, to Wipro is Satyam, to Zylog is Infotech, to Tech Mahindra is Mphasis, to Vankragee is Tata Infotech, to Polaris is HP, to Flextronics is Persistent, to Acropetal is KPIT, to Hexaware is Flextronics, to KPIT is Acropetal and to Persistent, the closest company is Flextronics.

\begin{tabular}{|c|c|c|c|c|c|c|c|c|c|c|c|c|c|c|c|c|c|c|c|c|c|}
\hline & & " & in: & $\mathrm{m}$ & tre & In & in & Fr & $E$ & rinet & $1 \pi$ & $\pi 1$ & & 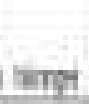 & $\sin$ & 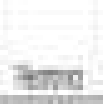 & $\mathrm{s}$ & mart & 位 & & $m$ \\
\hline & 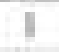 & 4 & $\mathbb{H}$ & 폴 & 4 & 11 & If & 15 & II & Ш & $\mathbb{E}$ & $I$ & I & II & 4 & H & 4 & 15 & If & 1 & 40 \\
\hline & & i & III & 13 & H & II & 1 & III & II & 1 & if & 1 & 11 & it & 且 & a & II & 1 & II & II & 4 \\
\hline & & 15 & 1 & 1 & II & 4 & II & 15 & 11 & & IE & 4 & II & II & II & $\mathrm{H}$ & $=$ & I & ir & II & II \\
\hline$x$ & 4 & 3 & $\mu$ & 1 & if & 15 & $\mathbb{L}$ & if & III & $\Psi$ & II. & 4 & I & 2 & 4 & 4 & 19. & 4 & it & 4 & 4 \\
\hline $4=$ & 4 & 4 & 11 & M & i & II & it & 12 & 世 & H & IE: & $y$ & 19 & 4 & 11 & 1 & 4 & it & II & if & t \\
\hline Di. & & I & 1 & II & iI & I & 14 & $=$ & III & H & it & 1 & ii & II & 3 & $\mathbf{u}$ & $\pi$ & 4 & Lt & II & I \\
\hline & & 1 & 11 & 1 & 1H & 1 & 1 & IH & HI & If & II & 1 & 1 & $H$ & $\omega$ & 4 & II & II & it & - & 4 \\
\hline$r$ & If & Q & $\mathbb{I I}$ & II & 11 & $\mathrm{i}$ & D & 1 & A. & it & II & $A$ & 7 & 1 & 4 & I & 3 & II & H4 & 1 & It \\
\hline & & $x$ & 1 & II & 14 & 1 & IV & 1 & 1 & 4 & II & 1 & 1 & I & $D$ & \pm & & 11 & $D$ & & \\
\hline 45 & If & 불 & II & 14 & 11 & 4 & Hi & 1 & 14 & & it & 4 & H & 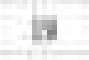 & 4 & 11 & 11 & II & II & II & 4 \\
\hline 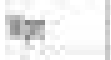 & II & 11 & 18 & $x$ & II & 1 & II & II & 11 & & 1 & 4 & 13 & II & U & II & & II & II & & II \\
\hline & y & L & it & $E$ & H & 11 & 1 & $\mathbb{A}$ & E & 13 & 4 & 1 & & & $\mathrm{~g}$ & & & L & 11 & & H \\
\hline alleth & 4 & DI & In & 9. & $\underline{E}$ & $\mu$ & 4 & 4 & III & 벼 & 4 & $\mu$ & & 1 & II & & 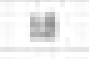 & 11 & II & 4 & L \\
\hline npa & 1 & $y$ & II & 1 & If & . & II & it & II & & 11 & L & $\Delta$ & & 14 & & & 1 & Lit & 4 & \\
\hline 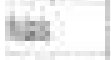 & $H$ & 1 & II. & $\Delta$ & IN & 1 & IF & II & 11 & 1 & II & 0 & 1 & II & 1 & 4 & I & $L$ & 1 & 1 & $\mathrm{H}$ \\
\hline ani & $\Psi$ & $\square$ & If. & 4 & it & 3 & II & II & DI & 14 & 11 & 1 & 4 & 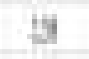 & 11 & & 4 & 14 & 14 & III & 4 \\
\hline & If & $\square$ & II & u & 4 & 11 & it: & II & II & 4 & II & 1 & 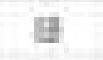 & 3 & 吾 & 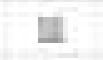 & 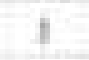 & $\mathbf{D}$ & 13 & If: & 4 \\
\hline 4 & 4 & $\Perp$ & III & 4 & It & 11 & IF & II & III & 4 & 4 & $=$ & 4 & 4 & 4 & $=$ & 1 & 1 & 1 & 4 & It \\
\hline (1) & if & II & II & 4 & $\Delta$ & 1 & 7 & it & $\mathrm{D}$ & H & if & 11 & 4 & 4 & 11 & 료 & it & 1 & 1 & 1 & it \\
\hline$n \rightarrow$ & 4 & 14 & L & 4 & 4 & 11 & I) & 1 & DI & 4 & if & 1 & $\mathbf{L}$ & It & 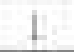 & 11 & 11 & II & 14 & 1 & \\
\hline
\end{tabular}

In next step, the ideal value for each indicator is evaluated which is maximum for a positive effect of the indicator on the performance of the company and minimum for the negative effect of the indicator on the performance. Following are the ideal values for each variable: 
Table 4: Ideal Values (O) for each variable

\begin{tabular}{|l|c|c|c|c|c|c|c|c|c|c|}
\hline Indicator & EPS & $\begin{array}{c}\text { Curren } \\
\text { t Ratio }\end{array}$ & $\begin{array}{c}\text { Net } \\
\text { Profit }\end{array}$ & $\begin{array}{c}\text { Sales } \\
\text { ratio }\end{array}$ & $\begin{array}{c}\text { Net } \\
\text { Profit } \\
\text { Ratio }\end{array}$ & Turnover & $\begin{array}{c}\text { Expense } \\
\text { Ratio }\end{array}$ & $\begin{array}{c}\text { Return } \\
\text { On } \\
\text { Assets }\end{array}$ & $\begin{array}{c}\text { Enterprise } \\
\text { value }\end{array}$ & $\begin{array}{c}\text { Wages } \\
\text {-to- } \\
\text { Sales } \\
\text { Ratio }\end{array}$ \\
\hline Ideal & 2.80 & 2.06 & 3.21 & 3.16 & 2.15 & 2.37 & -2.22 & 2.71 & 3.78 & -3.02 \\
\hline
\end{tabular}

Now, the Matrix 5 is obtained after subtracting each company variable from ideal ones. The matrix indicates the distance from the ideal value. It is useful in determining the profitability of the company.

Table 5/ Matrix 5: Distance from Each Company to Ideal (O)

\begin{tabular}{|l|c|c|c|c|c|c|c|c|c|c|}
\hline Company Name & EPS & $\begin{array}{c}\text { Current } \\
\text { Ratio }\end{array}$ & $\begin{array}{c}\text { Net } \\
\text { Profit }\end{array}$ & $\begin{array}{c}\text { Sales } \\
\text { ratio }\end{array}$ & $\begin{array}{c}\text { Net Profit } \\
\text { Ratio }\end{array}$ & Turnover & $\begin{array}{c}\text { Expense } \\
\text { Ratio }\end{array}$ & $\begin{array}{c}\text { Return On } \\
\text { Assets }\end{array}$ & $\begin{array}{c}\text { Enterprise } \\
\text { value }\end{array}$ & $\begin{array}{c}\text { Wages-to- } \\
\text { Sales Ratio }\end{array}$ \\
\hline H C L & 9.84 & 9.95 & 9.94 & 4.78 & 2.73 & 7.07 & 1.70 & 9.20 & 11.79 & 8.26 \\
\hline H P & 9.85 & 0.52 & 13.62 & 12.24 & 12.03 & 8.53 & 11.73 & 0.90 & 17.66 & 17.34 \\
\hline Infosys & 0 & 0.04 & 1.14 & 7.95 & 1.68 & 1.73 & 1.75 & 6.85 & 6.50 & 12.30 \\
\hline Infotech & 11.64 & 1.52 & 13.44 & 11.53 & 4.82 & 8.61 & 4.73 & 8.97 & 17.71 & 9.67 \\
\hline Mphasis & 9.82 & 8.18 & 12.54 & 5.92 & 4.98 & 7.81 & 5.77 & 9.87 & 17.27 & 7.63 \\
\hline Oracle & 0.95 & 2.48 & 11.70 & 0.00 & 0.00 & 8.53 & 2.14 & 18.19 & 16.08 & 10.06 \\
\hline Patni & 8.49 & 11.42 & 12.77 & 12.20 & 2.23 & 8.16 & 2.74 & 13.96 & 17.43 & 14.71 \\
\hline Satyam & 13.58 & 8.65 & 11.35 & 12.44 & 3.47 & 0.00 & 11.20 & 6.69 & 16.99 & 15.47 \\
\hline TCS & 5.04 & 4.95 & 0.00 & 7.12 & 1.20 & 0.00 & 0.60 & 3.22 & 0.00 & 10.27 \\
\hline Tata Infotech & 8.05 & 7.20 & 13.66 & 19.97 & 9.52 & 8.61 & 10.97 & 0.00 & 17.76 & 1.47 \\
\hline Wipro & 10.64 & 5.07 & 4.31 & 7.45 & 5.15 & 0.45 & 5.28 & 7.82 & 9.06 & 9.67 \\
\hline Zylog & 1.61 & 0.00 & 13.46 & 18.84 & 6.83 & 8.59 & 4.91 & 8.81 & 17.85 & 3.66 \\
\hline Tech Mahindra & 6.71 & 9.33 & 12.46 & 13.78 & 9.24 & 4.47 & 7.85 & 8.18 & 14.85 & 7.29 \\
\hline Vakrangee & 14.13 & 0.98 & 13.60 & 19.40 & 12.40 & 8.07 & 12.06 & 3.46 & 17.56 & 0.00 \\
\hline Polaris & 11.62 & 8.35 & 13.48 & 18.27 & 10.82 & 8.20 & 11.01 & 3.77 & 17.79 & 22.41 \\
\hline Flextronics & 6.80 & 6.31 & 13.54 & 8.16 & 3.51 & 8.51 & 1.24 & 9.83 & 17.69 & 9.30 \\
\hline Acropetal & 13.26 & 4.25 & 13.77 & 15.40 & 6.07 & 8.66 & 8.31 & 15.00 & 17.87 & 10.90 \\
\hline Hexaware & 12.82 & 8.59 & 13.22 & 7.21 & 0.25 & 8.49 & 0.00 & 9.87 & 17.58 & 9.37 \\
\hline K PI T & 13.55 & 5.92 & 13.61 & 9.00 & 6.75 & 8.55 & 4.83 & 13.85 & 17.65 & 10.43 \\
\hline Persistent & 7.40 & 3.93 & 13.44 & 7.12 & 4.47 & 8.30 & 4.14 & 7.15 & 17.68 & 9.75 \\
\hline
\end{tabular}

Table 6 consists of the pattern (cio) and measure (di) of profitability. The larger the value of cio the greater is the distance from this particular company to its potential high point within the set or subset. On the other hand, the closer $\mathrm{d}$ is to 0 , the more profitable is the company and the closer to 1 , the less profitable the company. 
Table 6 / Matrix 6 : Pattern and Measure of Profitability

\begin{tabular}{|c|c|c|}
\hline $\begin{array}{l}\text { Company } \\
\text { Name }\end{array}$ & $\begin{array}{l}\text { Pattern } \\
\left(c_{\text {io }}\right)\end{array}$ & $\begin{array}{l}\text { Measure } \\
\left(d_{i}\right)\end{array}$ \\
\hline $\mathrm{HCL}$ & 3.39 & 0.47 \\
\hline HP & 5.88 & 0.81 \\
\hline Infosys & 4.14 & 0.57 \\
\hline Infotech & 4.72 & 0.65 \\
\hline Mphasis & 3.69 & 0.51 \\
\hline Oracle & 6.83 & 0.94 \\
\hline Patni & 5.00 & 0.69 \\
\hline Satyam & 5.33 & 0.74 \\
\hline TCS & 3.55 & 0.49 \\
\hline Tata Infotech & 6.32 & 0.87 \\
\hline Wipro & 3.04 & 0.42 \\
\hline Zylog & 6.48 & 0.89 \\
\hline Tech Mahindra & 3.30 & 0.46 \\
\hline Vakrangee & 6.78 & 0.94 \\
\hline Polaris & 5.56 & 0.77 \\
\hline Flextronics & 4.69 & 0.65 \\
\hline Acropetal & 4.43 & 0.61 \\
\hline Hexaware & 5.45 & 0.75 \\
\hline $\mathrm{KPIT}$ & 4.14 & 0.57 \\
\hline Persistent & 4.36 & 0.60 \\
\hline
\end{tabular}

Clearly from the Table 6 above, Wipro has the highest profitability and is the best performing company among the set taken with the $d$ value of 0.42 followed by HCL, Tech Mahindra, TCS and Infosys. The least performing companies are Oracle and Vakrangee with the d value to be closest to 1 and with the larger pattern value. Finally, the cluster analysis is represented by the Figure 1 . The figure is hierarchal clustering with the highest place occupied by TCS. There are three clusters indicated as first cluster having TCS as the only performer member, the second cluster contains Infosys and Wipro as the members implying that both are almost similar in performance and profitability and final cluster consists of all the rest 17 companies showing similar nature. Cluster Analysis reveals that Tata Consultancy Services (TCS) is over and above every other company and is standing alone in the cluster. Moreover, Infosys and Wipro are second best players of the market in the IT sector. 


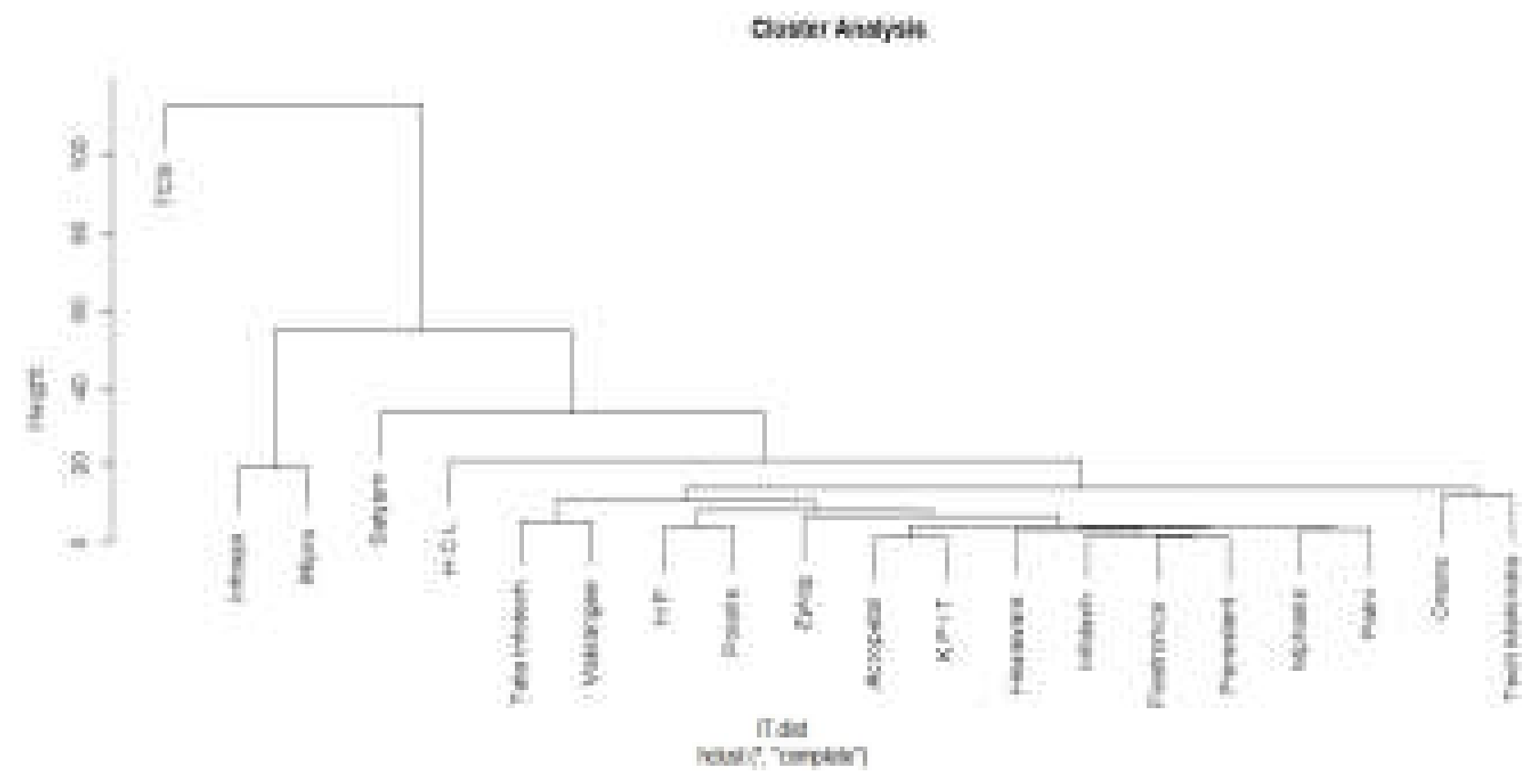

\section{Conclusion}

The paper applies a taxonomy method to analyse the profitability of the companies in the IT sector based on the performance indicators. The purpose of this research is to integrate and extend the method for evaluating the company performance based on the various indicators. The findings of the method reveals that Wipro is the best performer and more profitable out of the set of 20 companies while cluster analysis summarized that TCS is the only one in its own category whereas Wipro and Infosys are almost identical companies.

The biggest limitation of the method is that it can be applied to only homogeneous set of companies. However, this taxonomy proposes a method to study and synthesize the behaviour of companies in a simple manner. In the future, the further research can be carried in trying to overcome the limitation and also, the classification and comparison scheme can be refined with more methodologies like network neural analysis to be able to compare different units of different sectors.

\section{References}

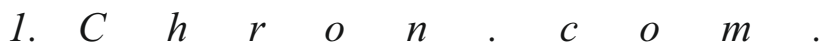
$<$ http://smallbusiness.chron.com/ wagessales-ratio-12713. html>.

2. Coccia, Mario. "A New Taxonomy of Country Performance and Risk Based on Economic and Technological Indicators." Journal of Applied Economics Vol X, No. 1 (May 2007): 29-42.

3. D'Amato, Elio. The Top 15 Financial Ratios. Australian Shareholder's Association, n.d.

4. Drake, Pamela Peterson. "Financial Ratio Analysis." n.d.

5. "Investopedia."

$<$ http://www.investopedia.com /university/ratios/landing.asp>.

6. Kumar, Subash Sharma and Ajith. "Cluster Analysis and Factor Analysis." n.d.

7. Appendix I. "Taxonomic Method".

8. “Cluster Analysis." < http://www. stat.berkeley.edu/ classes/s133/Cluster2a.html>. 